\title{
As Estratégias do Entrevistador: análise da questão 102 do QFF em cinco capitais do Nordeste
}

\author{
Fabiane Cristina ALTINO* \\ Reinaldo César ZANARDI**
}

\begin{abstract}
* Doutorado em Estudos da Linguagem pela Universidade Estadual de Londrina (2007). Pós-doutorado na Universidade Paris 13 - França (2011) e na Universidade Federal do Rio de Janeiro (2015). Docente da Universidade Estadual de Londrina. Contato: fabiane_altino@uol.com.br.

** Mestrado em Comunicação (2012) pela Universidade Estadual de Londrina. Doutorando em Estudos da Linguagem na Universidade Estadual de Londrina. Professor Colaborador do Curso de Jornalismo da Universidade Estadual de Londrina. Contato: rczanardi@gmail.com.
\end{abstract}

\section{Resumo:}

Os estudos geolinguísticos e dialetológicos compreendem várias etapas, como a definição do objeto de estudo, o objetivo, a metodologia, o perfil e a seleção dos informantes, a definição e a preparação dos entrevistadores, o financiamento, o preparo do material para a realização das entrevistas, o estabelecimento de pontos de contato, a seleção dos informantes, a realização das entrevistas, entre outras. Entre os autores que discorrem sobre as etapas desse trabalho estão Brandão (1991), Aragão (1998), Ferreira (1998), Aguilera (1998) e Caruso (2005). Para este estudo interessa a realização da entrevista em pesquisa de campo. O objetivo deste artigo é analisar as estratégias do inquiridor para obter respostas adequadas junto aos informantes. O corpus desta pesquisa considera as 40 entrevistas do Atlas Linguístico do Brasil (ALiB) em cinco capitais da Região Nordeste: Salvador (BA), Aracaju (SE), Maceió (AL), Recife (PE) e João Pessoa (PB). O levantamento de dados consistiu na análise da questão 102 do QFF. Do corpus analisado, os entrevistadores conseguiram a resposta desejada em 29 entrevistas, um total de $72,5 \%$. Os resultados apontam para estratégias diversas do inquiridor para a obtenção da resposta esperada.

\section{Palavras-chave:}

Estudos geolinguísticos. Dialetologia. Estratégias do inquiridor.

Signum: Estudos da Linguagem, Londrina, v. 21, n. 1, p. 55-71, abr. 2018 


\section{As Estratégias do Entrevistador: análise da questão 102 do QFF em cinco capitais do Nordeste}

Fabiane Cristina Altino; Reinaldo César Zanardi

\section{INTRODUÇÃo}

Um atlas linguístico, como produto de estudos geolinguísticos e dialetológicos, pressupõe a realização de um trabalho minucioso, organizado e sistematizado para que dados sejam expostos em formato de mapas (cartas linguísticas) e possam fornecer informações no âmbito da diatopia sobre traços semânticos, lexicais, morfossintáticos e fonéticos.

O trabalho anterior à apresentação dos mapas e cartas de um atlas linguístico consiste em uma tarefa cujas etapas devem ser muito bem planejadas. Entre essas etapas estão a definição do objeto de estudo, os objetivos, a metodologia - incluindo a redes de pontos, os instrumentos de coleta de dados, o perfil dos informantes, a definição e a preparação dos entrevistadores ${ }^{1}$-, o financiamento, o preparo do material para a realização das entrevistas - álbuns de figuras e reália, o estabelecimento de pontos de contato, a seleção dos informantes e a realização das entrevistas. Depois dessas etapas, é necessário transcrever o material coletado e revisar as entrevistas gravadas.

De todas as etapas para a realização de um atlas linguístico, interessa a este artigo a realização dos inquéritos junto aos informantes selecionados. Brandão (1991, p. 31-32) afirma que, na realização de um atlas, é preciso, nas entrevistas com os informantes selecionados, obter um material homogêneo, que possa servir de comparação. A autora cita que o instrumento de coleta de dados mais indicado é o questionário estruturado, usado como fio condutor da investigação.

A formulação das perguntas depende, antes de tudo, dos objetivos do projeto. $\mathrm{O}$ pesquisador deve ter claro se visa ao estudo de aspectos fonéticos, lexicais e/ou morfossintáticos e, ainda se quer imprimir ao atlas um cunho etnográfico. Assim, na elaboração do questionário, mostra-se mais uma vez, de grande importância a etapa aqui denominada 'levantamento preliminar de dados', pois a tarefa, ao contrário do que possa parecer, não é simples (BRANDÃO, 1991, p. 32).

A literatura sobre Geolinguística e Dialetologia - com detalhamento das diferentes etapas - aborda de forma precisa a elaboração dos questionários e os cuidados que os pesquisadores devem ter nesse momento.

\footnotetext{
${ }^{1}$ Neste artigo utilizamos os termos entrevistador, inquiridor e documentador como sinônimos.
} 
não há normas extremamente restritivas para a sua organização. No entanto, alguns critérios gerais devem ser observados no que podem servir de diretrizes as recomendações de José Joaquim Montes em Dialectología general e hispano-americana (BRANDÃO, 1991, p. 33).

Entre as recomendações sintetizadas por Brandão (1991), duas delas destacam-se à consecução deste artigo. Trata-se de elementos indispensáveis para a boa preparação do instrumento de coleta de dados e de formação de uma equipe de inquiridores consolidada.

As pesquisas dialetológicas no Brasil centram-se em questionários onomasiológicos, ou seja, que partem dos conceitos para se chegar às variantes. Os pontos nucleares para a elaboração de questionários eficazes são a sua abrangência, a dimensão linguística que se quer registrar, a dimensão e a precisão lexical.

A primeira trata da abrangência: em territórios com grande variedade idiomática, pode-se elaborar questionários capazes de recobrir conceitos comuns aos territórios e outros, de especialidades, que reportarão a uma linguagem regional e/ ou profissionalizante. Teríamos, dessa forma, ao menos dois questionários diferentes: um geral, para todas as localidades, e outro específico, para determinadas regiões. Essa divisão é bastante útil, por um lado, para trabalhos que irão pormenorizar o léxico regional, e por outro, para os que têm como objetivo mapear o(s) falar(es) de um grupo maior de pessoas, como é o caso do Atlas Linguístico do Brasil - ALiB, que tem questionários gerais, buscando assim o mapeamento de termos em todo o território, centrando seu objetivo em mapear a realização/não realização de termos comuns.

A segunda trata da dimensão linguística. Os questionários, normalmente, articulamse em três dimensões: a lexical, que permite o conhecimento das variantes para um determinado referente; a fonética, que possibilita o registro das variações de pronúncia e da prosódia; e a gramatical, que permite a recolha de dados para a verificação dos usos morfossintáticos dos falantes de uma língua. Há, ainda, dimensões que podem medir o nível de atitude sobre a língua que se fala, o reconhecimento e o sentimento de pertencimento do falante sobre sua língua materna, os níveis de linguagem - formal, coloquial -, entre outros. A tarefa de preparação dos questionários - sua testagem em entrevistas piloto e refacção de questões que necessitem de uma elaboração mais acurada - antecede a ida a campo para a coleta dos dados.

Peça fundamental para que a recolha dos dados possa ser mais natural possível, o entrevistador precisa ser preparado para a aplicação dos questionários. Como mencionado por Tarallo (1985), para que se tenha dados de fala natural, embora em um ambiente pouco natural, o entrevistador se vê às voltas com o paradoxo do observador: como recolher dados naturais em uma situação tão artificial quanto a entrevista? Assim, a preparação da equipe que irá a campo na recolha dos dados merece igual atenção para a realização satisfatória de entrevistas. Para o ALiB, conforme Altino (2004), as questões cruciais para a preparação do inquiridor/documentador foram exaustivamente retomadas e a utilização de entrevistas piloto que pudessem preparar a equipe foi de grande valor. O rigor científico, a familiaridade 
com o instrumento de pesquisa, o estudo da localidade, a disposição para ouvir as falas dos informantes são condições sine qua non para o bom andamento da entrevista.

Para Brandão (1991, p. 35), no trabalho de campo, o entrevistador "deve pautar-se pelo máximo de rigor, a fim de que se garanta um corpus fidedigno”. A equipe de inquiridores deve ter sintonia e seu trabalho deve ser o mais homogêneo possível. Diante desse cenário, muitas vezes opta-se por um número diminuto de inquiridores para a manutenção de recolha uniformizada. Aguilera (1998) lembra que para o Atlas Linguístico da França, Gilliéron optou por um único entrevistador (Edmond Edmont) e, modernamente, como é o caso do Atlas Linguístico do Paraná, publicado em 1994, a autora considerou “indispensável realizar o trabalho de campo com um número reduzido de inquiridores para que a coleta fosse a mais homogênea possível" (AGUILERA, 1998, p. 113).

Embora um único entrevistador fosse o ideal, com as dimensões nacionais do ALiB essa prerrogativa não pode ser considerada. A defesa de vários investigadores na fase de levantamento de dados passou a ser constante para os estudos dialetológicos contemporâneos. A conduta similar, as possibilidades de reformulação de questões consideradas mais difíceis e a forma de conduzir os trabalhos passaram a ser o centro das atenções para a equipe e muitos encontros foram organizados para dirimir esses e outros problemas. $\mathrm{O}$ apuro metodológico adotado pela equipe do ALiB permitiu que as entrevistas realizadas servissem como parâmetro de refinamento das técnicas de entrevistas e sua análise de bússola para novos pesquisadores. Nesse sentido, o objetivo deste artigo é analisar a atuação do inquiridor na realização de entrevistas para a elaboração do Atlas Linguístico do Brasil.

Para analisar as estratégias do entrevistador ${ }^{2}$, considera-se a pergunta 102 do Questionário Fonético-Fonológico (QFF) do ALiB (CARDOSO et al., 2013, p. 79): “Quando duas pessoas têm um desentendimento, uma briga, um problema, elas procuram um juiz para resolver a___ Quando você / o(a) senhor (a) não quer muito uma coisa, vocêe / o(a) senhor(a) diz: Eu não faço___?', em que se espera a resposta [kes' tãw] / [kwes'tãw] / [kwes' tã]. Para o QFF é preciso que se faça uma ressalva: pela natureza do objeto do questionário, é necessário levar os entrevistados a responderem itens lexicais pré-estabelecidos (doravante indicada pela expressão resposta esperada), como no caso aqui estudado, em que todos os informantes serão levados a responder o item lexical questão em suas variações fonéticas.

Para este trabalho, a retomada da pergunta estudada ao final das entrevistas foi considerada separadamente. Adotamos essa metodologia pela própria retomada das perguntas, que, por si só, já é uma estratégia, definida e orientada pelo projeto, não sendo uma estratégia espontânea e individual do entrevistador no momento da coleta das informações, conforme o desenvolvimento de perguntas e respostas.

\footnotetext{
${ }^{2} \mathrm{O}$ presente artigo toma como base outros autores que já discutiram a metodologia de coleta de dados do ALiB. O estado da arte, aqui mencionado, serviu em grande medida para o aprimoramento dos autores deste artigo e para o arcabouço teórico-metodológico na análise das respostas registradas para a questão 102, nosso objeto de estudo.
} 
Para a composição do corpus deste estudo, foram selecionadas as entrevistas realizadas em cinco capitais do Nordeste brasileiro: João Pessoa, capital da Paraíba; Recife, de Pernambuco; Maceió, de Alagoas; Aracaju, de Sergipe; e Salvador, da Bahia. Foram investigadas as respostas de 40 informantes, com distribuição equânime entre as localidades, divididos em: a) duas faixas etárias: 18 a 30 anos e 50 a 65 anos; b) sexo masculino e feminino; c) escolaridade: ensino fundamental e ensino universitário.

Sobre a abordagem e metodologia para a coleta de dados, Ferreira (1998, p. 20), citando os procedimentos de coleta de dados e os resultados do Atlas Prévio dos Falares Baiano - APFB, obra modelar para o ALiB, aponta para situações que devem ser tomadas como praxe para o inquiridor. Duas delas dizem respeito à conduta adotada para o ALiB: a forma de produção dos enunciados e as reformulações. Na primeira, a formulação padrão, que permite homogeneizar a amostra, é a sugestão inicial de conduta. Para a questão 102, pela natureza da resposta, o próprio questionário já sugere uma segunda reformulação. Não obtida a resposta esperada, o inquiridor lançará mão de novas sugestões para a obtenção do item. Há que se tomar cuidado, nesta etapa da coleta de dados, para não exaurir o informante com muitas tentativas. Essas duas recomendações sugerem uma conversa informal, sem extrapolar os limites da tolerância do informante. Se necessário, o inquiridor, na retomada ao final, deverá fazer nova tentativa de recolha do item. Relembrando ainda as palavras de Brandão (1991), deve-se ter atenção redobrada para não induzir o informante à resposta esperada e portar-se de maneira neutra, para que a sua fala não sirva de exemplo ou imitação para o informante.

Tendo como pontos norteadores as anotações acima, este artigo faz a análise das estratégias para a obtenção do item / keStãw/, objeto da pergunta 102 do QFF, detalhadas na próxima seção.

\section{O Que nos Contam os Dados}

Para verificar as estratégias do entrevistador quanto à obtenção da resposta esperada para a pergunta 102 , inicialmente faz-se necessária a organização quantitativa das respostas. Do total de 40 entrevistas, em 29 delas $(72,5 \%)$ a resposta esperada foi obtida nas primeiras formulações da questão, e em 11 (27,5\%), não respostas.

Salienta-se que $27,5 \%$ dos entrevistados não responderem conforme o esperado à pergunta 102 do QFF do ALiB, e esse fato nos remete a questionamentos como: i) o informante não reconhece o termo, por isso não respondeu ao entrevistador; ii) $\mathrm{o}$ informante utiliza outras palavras para a designação que se pede, uma vez que os informantes apresentaram como variantes linguísticas: causa, briga, ação, problema, processo, situação; iii) falta de destreza do entrevistador ao conduzir o inquérito; ou iv) a pergunta foi mal elaborada (quando da formulação dos questionários).

Para as questões (i) e (ii), postas como possíveis motivações para a não resposta esperada, abriram-se caminhos plausíveis e constatados em outros campos que remetem à 
variação: a não resposta é uma resposta à medida que verificamos que determinados itens lexicais (ou de outra natureza) não são realizados em determinados espaços (físicos ou sociais); e, por conta disso, a utilização de outros termos na língua para a referenciação.

Quanto aos itens (iii) e (iv) das anotações, a não resposta esperada viria de inabilidade (do inquiridor e/ou do questionário), causas passíveis de análise metodológica pelos participantes do projeto e da busca para sanear problemas.

Voltando para os dados, quantitativamente, no panorama dos entrevistados que não responderam à questão analisada, a variável diassexual não foi significativa. Dos 11 informantes que não responderam, 6 são homens e 5 são mulheres. Quando analisamos as variáveis, contabilizamos o seguinte panorama: 6 jovens e 5 idosos e 7 com ensino fundamental e 4 com ensino superior. Diageracionalmente, as diferenças também não são representativas, porém, quando olhamos para os dados da perspectiva diastrática, os indicadores começam a delinear um quadro que poderemos explorar. Provavelmente a palavra questão não seja muito comum ao vocabulário dos informantes com menor grau de escolaridade. Outra hipótese que nos é lançada refere-se à variável diatópica, ou seja, pode não estar no vocabulário ativo na região estudada. Isso pode ser reforçado pelo fato de que somente em nove entrevistas deste corpus a lexia foi apontada em primeira resposta, sendo esta a mais espontânea, como será discutido mais à frente, neste artigo.

Essa impressão é confirmada por estudo de Aguilera e Yida (2008) que, a partir da escolaridade dos informantes (ensino fundamental e superior), analisaram, em corpus de 25 capitais brasileiras, as respostas e a ausência de respostas nas 159 perguntas do QFF do ALiB. Ao analisarem as respostas dos informantes de nível fundamental, as autoras afirmam parte das questões do QFF (como casa, abelha, Brasil...) propiciam fácil obtenção de respostas junto aos informantes e esta facilidade pode estar relacionada "com o fato de serem palavras de alta freqüência de uso e com poucas possibilidades de múltipla escolha" (AGUILERA; YIDA, 2008, p. 19). Ainda segundo as autoras, as outras questões (a maioria do QFF), quando aplicadas aos informantes com escolaridade mais baixa, podem apresentar obstáculos na obtenção das respostas esperadas. Esse é o caso da questão analisada neste artigo, que podem "ser preenchidas por parassinônimos mais freqüentes na fala dos informantes" (AGUILERA; YIDA, 2008, p. 20). É possível, portanto, afirmar que entre as causas para a não obtenção da resposta esperada estão o fato de as palavras serem pouco usadas no cotidiano dos informantes, além de as perguntas propiciarem múltipla escolha. Segundo as autoras, as não respostas de informantes com ensino fundamental não diferem muito do perfil dos entrevistados com nível superior.

As não-respostas, dentre os informantes de nível superior, apresentam um perfil semelhante ao dos informantes de nível fundamental se se considerar a natureza das questões, pois, em sua maioria, os itens lexicais se repetem junto aos informantes de um e de outro nível de escolaridade (AGUILERA; YIDA, 2008, p. 23). 
A questão 102 do QFF, objeto deste estudo, no levantamento de Aguilera e Yida (2008), figura entre as principais questões não produtivas, distribuídas por região. Na Região Nordeste, o índice atinge 22\%, entre os informantes com ensino fundamental e $8 \%$ entre aqueles com ensino superior.

Voltando para os números desta pesquisa, das 11 respostas não esperadas (não respostas ou parassinônimos), $36 \%$ foram dadas por informantes com ensino superior e $64 \%$ por informantes com ensino fundamental, índices que vão ao encontro dos dados da pesquisa de Aguilera e Yida (2008).

As hipóteses (iii) e (iv), que versam sobre a habilidade do inquiridor na obtenção da resposta, são alicerçadas na possibilidade de preparação do instrumento de coleta de dados ou do entrevistador. Sobre a questão propriamente dita, a equipe do ALiB, após a elaboração dos questionários, realizou entrevistas experimentais e voltou ao trabalho de gabinete para a elaboração de um instrumento que pudesse abranger todo o território nacional. Todo o empenho resultou em obra icônica para a Geolinguística nacional e seus questionários vêm sendo adotados, com ou sem adaptações, por muitos pesquisadores pelo Brasil afora. Naturalmente, como preconizava Nascentes (1958), o melhor questionário será redigido e aplicado quando o trabalho terminar. Todas as estruturas terão sido testadas e postas à prova do seleto grupo de informantes que nos direcionarão para a elaboração de um instrumento melhor. A este ponto, nossa coleta estará terminada e nos restará fazer um bom uso dos nossos maus dados, para lembrar Labov (1972).

Entre as causas para as não respostas, cabe-nos comentar a habilidade e a preparação do entrevistador. O ALiB, durante seus 20 anos de existência, tem buscado a formação continuada de todos os segmentos necessários para o andamento do projeto. Dentro dessa perspectiva, a preparação dos inquiridores tem recebido atenção especial. São pontos destacados a habilidade e a desenvoltura para conduzir as entrevistas, além de primar pela aptidão de resolver (ou contornar) problemas durante a entrevista, como se pode verificar no texto de Altino (2004), que trata dos procedimentos metodológicos e faz a historiografia dos acontecimentos até aquele momento para a preparação dos entrevistadores, constante do II Workshop do ALiB (2000). Isquerdo (2004, p. 51), tratando também dos procedimentos metodológicos para a realização definitiva de entrevistas, afirma que

O alcance deste intento pressupõe o domínio de cada pergunta com vista a se evitar a leitura das questões, como também a construção de reformulações alternativas prévias para se poupar improvisações quando houver a necessidade de refazer a pergunta para garantir a obtenção da resposta esperada (ISQUERDO, 2004, p. 51).

Aguilera e Yida (2008) relatam a trajetória do projeto no que diz respeito à capacitação de seus inquiridores e salientam a dedicação dos dirigentes para a formação de uma equipe homogênea e eficiente na captação dos dados in loco. 
Sobre este aspecto, o ALiB dedicou atenção especial reiterando aos Diretores científicos não só a necessidade de preparação da equipe de entrevistadores como a obrigatoriedade de cada candidato passar pelo aceite do Comitê Nacional mediante o envio de uma entrevista-teste. Esta entrevista, depois de analisada e aceita, volta para o candidato que deverá observar as recomendações, para então poder integrar a equipe de investigadores de campo (AGUILERA; YIDA, 2008, p. 28).

Além disso, o Comitê Nacional do ALiB limitou o número de entrevistadores, que não deveria passar de 30. Segundo recomendações, cada inquiridor deveria realizar, pelo menos, 30 entrevistas, embora, efetivamente, ter contado com um número maior de inquiridores. Isso se deu pela extensão territorial, pela dificuldade de manutenção nos projetos de alunos da graduação, enfim, pela alta rotatividade já conhecida no mundo acadêmico. Dados recentes constantes no Documentos 7, publicação oficial do ALiB, demonstram a persistência dessa definição, a tentativa de realização das entrevistas com número reduzido de entrevistadores e comentam os resultados dos 20 primeiros anos do Projeto. A título de exemplificação, a equipe Paraná "preparou doze investigadores dos quais sete realizaram, cada qual, mais de 15 entrevistas e três deles mais de 50" (AGUILERA; ALTINO; ROMANO, 2017, p. 117).

\section{As EstratégIAS do INQUIRIDOR}

Do total de entrevistas (40) selecionadas para este artigo, a resposta esperada foi registrada em 29 entrevistas, sendo que em 9 delas o inquiridor conseguiu a resposta [kes' tãw] / [kwes'tãw] / [kwes'tã] na primeira formulação da pergunta, o que representa 22,5\% do total de informantes. Esses dados reforçam a necessidade de, no momento da realização da entrevista, o inquiridor rever suas estratégias para conseguir a resposta desejada. Para a reformulação da pergunta 102 do QFF, podemos sintetizar as iniciativas para a obtenção do item esperado desta forma: oito informantes chegaram à resposta esperada na segunda formulação da pergunta, mesmo número de obtenção de resposta para as entrevistas em que o inquiridor precisou reformular por três vezes a pergunta; quatro tentativas de formulação para a obtenção do item em uma entrevista; cinco tentativas em duas entrevistas e sete tentativas em uma entrevista. É preciso salientar, neste ponto, as instruções para a retomada de questões, para que a busca pela resposta esperada não ultrapasse o limite tênue entre a busca pelos termos e o incômodo que se pode causar. Para não incorrer neste erro, o inquiridor é orientado a retomar, ao final da entrevista a questão que ficar em branco. Esta estratégia será discutida mais adiante neste artigo.

Vale registrar que, junto aos 29 informantes que deram a resposta esperada, foram realizadas, no total, 70 tentativas pelos entrevistadores. Isso representa uma média de 2,41 tentativas por informante. O número mínimo de tentativa foi uma e o máximo, sete. Já a média de tentativas junto aos informantes que não responderam dentro da expectativa de resposta é de 3,54 tentativas por informante. Ao todo, foram 39 tentativas para 11 informantes, sendo o máximo de dez tentativas em uma única entrevista. 
Sem exceção, os entrevistadores seguiram o roteiro do QFF. Em primeira tentativa, todos fizeram a pergunta conforme a formulação sugerida no questionário: "Quando duas pessoas têm um desentendimento, uma briga, um problema, elas procuram um juizpara resolver a

(CARDOSO et al., 2013, p. 79).

Quando o entrevistador não obtinha a resposta ou o informante dava reposta não esperada, uma estratégia comum era repetir a pergunta, refazendo-a de outra forma. O extrato da entrevista da informante jovem com ensino superior de João Pessoa corrobora o exposto. A informante não havia respondido à pergunta, permanecendo em silêncio.

INQ. ${ }^{3}$ - Brigou com alguém ou alguém deu calote em você, aí você parte para o juiz e vai resolver o quê?

INF.- O problema?

Outra estratégia bastante comum no corpus analisado e adotada pelos entrevistadores diz respeito à busca por sinônimo ou lexia equivalente quando o informante apresentava, por exemplo, causa, processo, briga ou desentendimento. A entrevista da mesma informante de João Pessoa é exemplo da estratégia usada pela inquiridora, em uma terceira tentativa.

INQ.- Sim, mas tem um nome específico pra isso?

INF.- Processo?

A busca por sinônimo ou lexia equivalente, diante de uma resposta não esperada, faz o entrevistador buscar alternativas, refazendo a pergunta, mais de uma vez, como é o caso da entrevista em Maceió, com o informante idoso de escolaridade superior, em que o inquiridor busca reformular a pergunta para a obtenção da resposta esperada: "Um... Ou outra maneira de dizer. (...) _ _ Vou resolver essa. (...) Pode ser causa, mas pode ser de outro jeito" (entrevista 7 do ponto 77). Outro exemplo está na entrevista feita com a informante idosa, com ensino superior:

INQ.- Tem outro nome? Tem um nome mais ou menos técnico pra ... pra... tenho uma ... na justiça.

INF.- uma causa!

INQ.- Tem outro nome, conhece outro nome pra isso?

INF.- uma ação.

Quando não obtinha a resposta ou se deparava com o informante apresentando reiteradamente respostas não esperadas, o entrevistador geralmente mudava o rumo da

\footnotetext{
${ }^{3}$ Nas transcrições: INQ refere-se ao inquiridor e INF ao informante.
} 
entrevista, usando a segunda parte da questão 102 do QFF como estratégia para a obtenção: "quando vocêlo(a) senhor (a) não quer muito uma coisa, você/ o(a) senhor(a) diæ: eu não faço

(CARDOSO et al., 2013, p. 79). Isso pode ser verificado nas entrevistas realizadas em Recife (ponto 70), com o informante jovem de escolaridade fundamental e com a informante jovem de escolaridade superior, respectivamente:

INQ.- E tem um/às vezes tem um dizer assim... quando a pessoa/não quero muito uma coisa, às vezes estou com uma coisa, você vem me diz eu posso pegar isso? Eu digo pode, eu não faço... Como é que eu digo? Eu não faço...

INF.- Não faço questão.

INQ.- E, quando você tem um objeto. Aí, você... Alguém quer aquilo. Sabe, leve. Não faço...?

INF.- Questão.

A estratégia de reformular a pergunta também era usada pelo entrevistador com a segunda parte da questão 102 do QFF. Em algumas ocasiões, o inquiridor tenta aproximar a situação do informante para torná-la mais pessoal e, assim, obter a resposta desejada. Isso pode ser verificado nos inquéritos de Maceió nas entrevistas do informante jovem com ensino fundamental e da informante idosa com ensino superior, respectivamente:

INQ.- Eu vou falar uma outra coisa. Por exemplo, quando você não quer muito uma coisa, aí você diz assim: eu não faço .... desse/dessa camisa.

INF.- (Silêncio).

INQ.- Pode levar.

INF.- Eu não faço mais nada?

INQ.- Digamos que.../você tem irmão?

INF.- Tenho.

INQ.- Aí, digamos... (...) que ele pegou sua camisa. Aí você chega pra ele.

INF.- Não faço mais uso dela.

INQ.- mas aí não, você até usa, mas você não (...). Aí, você diz assim.

INF.- Não faço questão.

INQ.- Vamos pensar assim. Você não quer muito uma coisa e você diz. Não, não quero isso. Não faço... como é que pode dizer?

INF.- Eu não faço, não quero de jeito nenhum.

INQ.- A pessoa tá lhe oferecendo uma coisa. Não, não, pode ficar eu não faço?

INF.- Não faço questão. 
$\mathrm{O}$ inquiridor mais atento pode também nem chegar a fazer o roteiro de perguntas conforme as sugestões da questão 102 do QFF. A partir do perfil do informante, ele pode dispensar a segunda parte da questão e formular o questionamento de modo totalmente diferente, conforme demonstrado a seguir, quando o entrevistador está diante da informante idosa com ensino superior, em Aracaju. Na primeira tentativa, a resposta não foi a esperada.

INQ.- Veja, quando é... como é o nome daquelas coisinhas que vem... Quando a gente faz um concurso, uma prova, alguma coisa assim, aí vem número 1, número $2 \ldots$

INF.- Questão.

Recorrer para o termo questão como equivalente de pergunta em uma prova, exame ou concurso também foi uma das estratégias utilizadas pelo entrevistador, nas várias tentativas - sem sucesso - com a informante jovem com escolaridade fundamental em Maceió:

INQ.- Não, quero que você pensa essa frase como você completa. Não! Você pode ficar com isso porque eu não faço disso. Não faço o quê?

INF.- Não faço esse tipo de coisa.

INQ.- Veja assim. Numa prova você faz um trabalho, o que é que você tem, você tem que resolver o que, que as pessoas...

INF.- O assunto.

INQ.- Cada pergunta, pergunta ou?

INF.- o dono?

INQ.- A prova tem tantas perguntas.

INF.- Sim.

INQ.- ou tem tantas.

INF.- Respostas.

INQ.- só perguntas, tem tantas perguntas ou tantas (...) essa prova tem tantas.

INF.- tem tantas o quê meu Deus?

INQ.- eu volto depois.

Mesmo com insistência e refazendo as estratégias para obter a resposta esperada, a entrevistadora não atingiu seu objetivo. Aguilera e Yida (2008), quando discutem a abstenção, levantam a hipótese de ela estar associada à personalidade do informante,

devido a diversos fatores, dentre os quais a baixa escolaridade, o conhecimento de mundo mais restrito e os de natureza psicológica, como timidez, cansaço, doença, desinteresse e mesmo problemas pessoais, como falta de tempo, assunção de outros compromissos para aquela ocasião, entre outros (AGUILERA; YIDA, 2008, p. 28). 
A análise da última transcrição também permite afirmar que o inquiridor foi perspicaz para refazer a pergunta, conforme o desenvolvimento da entrevista e a tomada de decisão de não mais insistir naquele momento foi acertada. A entonação, conforme o áudio, revela bastante informalidade. Essa característica está em consonância com o que Aragão (1998, p. 59) preconiza quando apresenta e discute o Atlas Linguístico da Paraíba: "As entrevistas foram realizadas o mais informalmente possível, havendo toda uma conversação preliminar em que se procurava deixar o informante descontraído e à vontade para responder às questões".

Mesmo com um trato informal, a entrevistada sentiu-se pressionada por não atender às expectativas do entrevistador, a partir da insistência com a mudança de foco da pergunta. Isso pode ser verificado na sua fala "tem tantas o quê, meu Deus?", que demonstra estar consciente de não ter conseguido corresponder à expectativa de resposta. Como se pode observar, a informalidade não é garantia de que o inquiridor vá obter a resposta. Caruso (2005, p. 376) lembra que

o próprio pesquisador é, para o Informante, um elemento estranho, um desconhecido, munido de gravador, lápis e papel, falando uma língua diferente da sua. É o que tem sido chamado de 'Paradoxo do Observador'. Lógico que é necessário, pelo menos, tentar anular essas 'armas'.

Sobre a atuação do investigador, Caruso (2005) recomenda que se conheça bem o questionário a ser aplicado e, também, a linguagem popular falada. Ele sugere que os inquiridores ouçam gravações já feitas para treinar o ouvido e aprender novas coisas. No entanto, situações não previstas sempre podem ocorrer.

É por isso que se diz que toda pesquisa de campo é um 'vôo cego', mesmo estando treinadíssimos, é possível defrontar-se com situações jamais imaginadas. (CARUSO, 2005, p. 378).

Quando os entrevistadores, mesmo lançando mão da segunda pergunta colocada à sua disposição no questionário, não obtêm a resposta esperada, novas estratégias entram em cena para o sucesso da entrevista. São estas alternativas que iremos tratar na seção seguinte.

\section{A Retomada como Estratégia do ALiB}

Uma das recomendações para o inquiridor, quando o informante não responde adequadamente, ou seja, não se obtém a resposta esperada, no que tange ao Questionário Fonético-Fonológico, é a da não insistência excessiva e a volta à pergunta ao final do questionário. Esta estratégia é válida para todas as perguntas que ficaram sem resposta e para todos os questionários aplicados. Portanto, quando o inquiridor deixa de insistir na 
busca por resposta e avisa o informante de que vai retomar a pergunta ao final da entrevista, está utilizando uma recomendação do Projeto, ou seja, não é uma estratégia espontânea do próprio inquiridor.

Essa estratégia, utilizada por dialetólogos em vários momentos, pode ter motivações diversas, como é o caso do APFB (1963 apud FERREIRA, 1998). Sobre o Atlas da Bahia, Ferreira (1998) relata a experiência das retomadas, mas com o objetivo de questionar aos informantes se conheciam determinado item lexical, apresentados por outros informantes da mesma rede de pontos, fazendo assim um teste de verificação.

Introduziu-se, todavia, uma metodologia não usual, em trabalhos dessa natureza. Após a aplicação integral do questionário, não ouvidas certas respostas e já familiarizados, como estavam todos os inquiridores, com expressões regionais obtidas em outras áreas, perguntou-se diretamente ao informante se ele conhecia a expressão em questão (FERREIRA, 1998, p. 20).

A retomada para apresentar ao informante itens lexicais ouvidos em uma determinada área também é registrada por Mota (1998) na elaboração do Atlas Linguístico de Sergipe: "após a aplicação integral do questionário, apresentaram-se aos informantes formas anteriormente ouvidas na área, solicitando-lhes informação sobre o seu significado e a sua utilização" (MOTA, 1998, p. 83).

A autora também ressalta que o teste de verificação não é uma metodologia usual na elaboração de atlas linguísticos e registra que "as formas ouvidas apenas na interrogação direta só foram cartografadas quando houve segurança sobre a sua identificação por parte do informante, como se comprova em notas" (MOTA, 1998, p. 83).

Como já dito, das 40 entrevistas realizadas a partir do corpus selecionado para este artigo, em 11 os inquiridores não conseguiram a resposta esperada para a pergunta 102 do QFF do ALiB. Sete informantes de João Pessoa, dois de Maceió, um de Aracaju e um de Salvador não registraram em suas falas a resposta esperada para a pergunta analisada neste artigo. Nas retomadas, a resposta esperada foi conseguida em apenas duas entrevistas, ou seja, com 18,18\% dos informantes, tendo como principal desencadeador da baixa produtividade das respostas o fato de o inquiridor não ter reformulado a pergunta 102 do QFF durante a retomada ao final do questionário. Das 11 entrevistas, em seis $(54,5 \%)$ a pergunta não foi realizada.

Nas cinco entrevistas em que a estratégia de retomada e reformulação pelo entrevistador foi realizada, a primeira tentativa foi a de refazer a primeira parte da pergunta 102 do QFF, ou seja, formular como está no questionário a pergunta para que o informante se lembrasse do contexto da questão.

A informante jovem com ensino fundamental de Maceió que não deu a resposta esperada durante a aplicação do questionário, respondeu na retomada em primeira tentativa. 
INQ.- As pessoas têm um briga/o vizinho tem uma briga e vai chamar o juiz para resolver a

INF.- a questão.

Já na entrevista feita com o informante idoso com escolaridade superior em Maceió, o inquiridor não obteve a resposta em primeira tentativa depois de ter feito a primeira parte da pergunta 102. No entanto, ao realizar uma nova tentativa, enfatizando o papel do juiz, ele obtém a resposta do informante.

INQ.- Chama o juiz pra resolver a

INF.- a questão.

$\mathrm{Na}$ retomada da entrevista de Aracaju, com o informante jovem de escolaridade fundamental, o inquiridor também realizou as duas formulações sugeridas da pergunta 102 do QFF, mas não usou o item lexical juiz. Neste caso, não obteve a resposta esperada, conforme transcrito a seguir:

INQ.- Aqui, a pessoa tem uma briga, um problema, chama alguém pra resolver a

INF.- (Silêncio)

INQ.- Quando você tem um briga, tem que chamar a pessoa pra resolver a

INF.- briga.

INQ.- ou então, você diz/uma coisa que não te interessa. Não, disso eu não faço

INF.- não quero, não faço.

Vale registrar que, dos sete informantes de João Pessoa que não responderam à pergunta 102, durante a aplicação do questionário inteiro não houve a menção ao léxico sugerido como resposta à questão estudada neste artigo. Em outras palavras, o termo questão não foi utilizado pelos sete informantes durante todos os questionários nem na retomada, sinalizando para a não utilização da palavra em situação de interlocução. O termo questão provavelmente não faz parte do repertório linguístico desses informantes, o que nos leva a questionar a utilização desse termo para a região.

Aguilera e Yida (2008) apresentam um aspecto importante para os estudos geolinguísticos: qual o limite aceitável de abstenções quando da realização das entrevistas? As autoras afirmam que não há conhecimento sobre a reação dos geolinguistas, do século passado, diante das não respostas, que segundo elas "deveriam ser comuns, principalmente porque os questionários eram muito extensos, chegando alguns a 5.000 questões" (AGUILERA; YIDA, 2008, p. 28). Sobre os atlas atuais brasileiros, as autoras enfatizam que as respostas não obtidas podem ter como raiz diversas possibilidades: problemas ocorridos 
na hora da gravação das entrevistas, como ruídos que possam prejudicar a audição; descuido do próprio entrevistador pela não realização da pergunta, tanto na entrevista quanto na retomada das questões; cansaço ou timidez do informante ou o desconhecimento do referente por parte do informante. Este último dado é importante para a Geolinguística, uma vez que o desconhecimento de um termo pode vir a demarcar uma área de não uso em comparação a outras que a utilizam, demarcando as isoglossas.

É evidente a importância do inquiridor na realização de um atlas linguístico. Ele é o elemento chave na coleta de dados junto aos informantes selecionados na rede de pontos definida e é a partir desses dados, ou seja, das formas apresentadas pelo informante, que serão processadas análises em estudos fonéticos, fonológicos, semânticos, lexicais e morfossintáticos. Vale ressaltar que o inquiridor, mesmo com treinamento, enfrenta um trabalho cansativo e situações para as quais ele pode não estar preparado. Para o questionário do ALiB são 500 perguntas por informante que, nem sempre, está disposto e disponível para responder a todas as perguntas. A sensibilidade de perceber o momento de sugerir uma pausa, quando avançar com o questionário, quando recuar e deixar uma questão para a reformulação e retomada ao final, faz toda a diferença no sucesso de um inquérito linguístico.

\section{CONSIDERAÇÕEs FinaIS}

O objetivo deste artigo foi avaliar as estratégias do entrevistador diante do informante na pergunta 102 do QFF, uma das dimensões do ALiB, no corpus composto pelas 40 entrevistas de cinco capitais do Nordeste: Salvador, Aracaju, Maceió, Recife e João Pessoa.

Como resultados, este estudo aponta as estratégias principais dos entrevistadores em duas situações distintas: quando a resposta não é a esperada e quando o informante não responde ao inquiridor.

No que se refere à resposta não esperada, prevalece a estratégia do entrevistador de buscar sinônimos ou lexias equivalentes à apresentada, inicialmente, pelo informante. Diante da não obtenção da resposta esperada, a pergunta é refeita com base na segunda parte/ sugestão da questão 102 do QFF.

Para as entrevistas do Nordeste aqui estudadas não foram utilizados outros referentes para a obtenção das respostas. Ou seja, os inquiridores não lançaram mão de outras situações em que o termo questão pudesse aparecer. Como exemplo, a matemática não foi requerida pelos entrevistadores como campo conceitual que pudesse oferecer a resposta esperada, como em "o que se resolve na prova de matemática?”. Ou, em outra situação, perguntar sobre "aquilo que é extremamente importante a gente diz que é uma de vida ou morte"; ou, ainda, outros momentos casuais em que se pode obter o item em pauta. Como o questionário fonético-fonológico visa à realização do fenômeno específico, no caso a realização de [kes'tãw] / [kwes'tãw], isto é, a possível realização do ditongo, tentar outras estratégias de obtenção do termo poderia significar o sucesso do registro. 
No que diz respeito ao não registro da resposta esperada, mesmo com as reformulações feitas pelos inquiridores, pode levar à conclusão da não utilização do termo por parte do informante. Em caso de recorrência, a hipótese de este termo estar no vocabulário passivo dos falantes pode ser ventilada pela baixa produtividade do item nas entrevistas realizadas. Esta hipótese poderá ser confirmada ou refutada com a análise das entrevistas do interior, verificando assim a abrangência do termo para a região estudada.

Nas duas situações apresentadas fica clara a importante característica dos entrevistadores do corpus analisado: a persistência na busca pela variante desejada. A persistência dos entrevistadores fica evidente na condução da entrevista que ocorre de forma natural, sem pressionar o informante.

Outro aspecto importante é a preocupação com a escolha vocabular. O que se pode verificar nas entrevistas realizadas em algumas das capitais nordestinas é o que Caruso (2005, p. 375-376) já preconizava, que "todo pesquisador busca encontrar a linguagem informal do seu informante, aquele tipo de linguagem que ele usaria com os seus amigos, com os seus familiares, enfim, no dia-a-dia".

Por mais que o inquiridor seja cuidadosamente preparado para a realização das entrevistas, algumas situações apresentadas no desenvolvimento do trabalho de campo não são previsíveis em sua totalidade. Em muitos casos, conseguir a resposta adequada vai depender da presença de espírito do investigador. Sua experiência profissional e de vida podem ser, em muitas situações, a pedra de toque para o sucesso do inquérito.

O ALiB hoje, com 100\% de suas entrevistas realizadas, comemora a boa formação de sua equipe de inquiridores, por realizar um trabalho minucioso que exige cuidados com os detalhes, dedicação e estudo dos questionários.

\section{Referências}

AGUILERA, V. de A. Atlas Lingüístico do Paraná: veredas. In: AGUILERA, V. de A. (Org.). A Geolingüística no Brasil: caminhos e perspectivas. Londrina: Ed. UEL, 1998. p. $99-133$.

AGUILERA, V. de A.; ALTiNO, F. C.; ROMANO, V. P. ALiB Paraná: 20 anos de estrada e estudos. In: CARDOSO, S. A. M. et al. (Org.). Documentos 7: ALiB 20 anos de história. Salvador: Quarteto, 2017. p. 115-138.

AGUILERA, V. de A.; YIDA, V. Projeto ALiB: uma análise das respostas e das não-respostas de informantes das capitais. Signum: Estudos da Linguagem, Londrina, v. 11, n. 2, p. 15-31, dez. 2008. Disponível em: < https://bit.ly/2rADmlN>. Acesso em: 23 jan. 2017. 
ALTINO, F. C. Avaliação dos procedimentos metodológicos: uma conversa sobre a conduta do inquiridor. In: AGUILERA, V. de A.; MOTA, J. A.; MILANI, G. A. L. Documentos 1: Projeto Atlas Lingüístico do Brasil. Salvador: EDUFBA, 2004. p. 55-62. ARAGÃO, M. do S. S. Atlas Lingüístico da Paraíba. In: AGUILERA, V. de A. (Org.). A Geolingüistica no Brasil: caminhos e perspectivas. Londrina: Ed. UEL, 1998. p. 55-77. BRANDÃO, S. F. A Geografia Lingüistica no Brasil. São Paulo: Ática, 1991.

CARDOSO, S. C. M. et al. (Org.). Documentos 4: Projeto Atlas Linguístico do Brasil. Salvador: Vento Leste, 2013.

CARUSO, P. Metodologia da pesquisa dialetológica. In: AGUILERA, V. de A. (Org.). A Geolingüistica no Brasil: trilhas percorridas, caminhos a percorrer. Londrina: Eduel, 2005. p. 371-380.

FERREIRA, C. Atlas Prévio dos Falares Baianos: alguns aspectos metodológicos. In: AGUILERA, V. de A. (Org.). A Geolingüistica no Brasil: caminhos e perspectivas. Londrina: Ed. UEL, 1998. p. 15-29.

ISQUERDO, A. N. Procedimentos metodológicos nas entrevistas definitivas: o entrevistador. In: AGUILERA, V. de A.; MOTA, J. A.; MILANI, G. A. L. Documentos 1: Projeto Atlas Lingüístico do Brasil. Salvador: EDUFBA, 2004. p. 45-54.

LABOV, W. Sociolinguistic patterns. Philadelphia: University of Pensylvania Press, 1972. MOTA, J. Atlas Lingüístico de Sergipe: aspectos metodológicos. In: AGUILERA, V. de A. (Org.). A Geolingïística no Brasil: caminhos e perspectivas. Londrina: Ed. UEL, 1998. p. $79-98$.

NASCENTES, A. Bases para a elaboração do Atlas Lingüistico do Brasil. Rio de Janeiro: Casa de Rui Barbosa, 1958.

TARALlO, F. A pesquisa sociolingüistica. São Paulo: Ática, 1985. 